\title{
A Conversation with Daniel Durocher
}

\author{
INTERVIEWER: JAN WITKOWSKI \\ Cold Spring Harbor Laboratory
}

Daniel Durocher is a Senior Investigator at the Lunenfeld-Tanenbaum Research Institute, Mount Sinai Hospital and the Faculty of Medicine, University of Toronto.

Jan Witkowski: Perhaps you could tell us a little bit about your work.

Dr. Durocher: It really is a continuation of our longstanding interest on how cells maintain the stability of the genome. Over the years, we've explored many aspects of it, but with the advent of using CRISPR as a genetic tool to really map out pathways, we've recently gone back and asked the questions: Do we have all the parts of DNA damage response proteins, and how can we find new ones? We've applied the CRISPR-based technology to do this, and it's been extremely successful.

Jan Witkowski: CRISPR is a very powerful technique. How are you using it? Are you knocking out genes at random and seeing the effect on repair? What strategy do you use?

Dr. Durocher: We're using guide RNA libraries. The guide RNA is the little piece of RNA that guides Cas9 to do cuts. We use these libraries in pools in lentiviruses, so that allows us to introduce them in cells very efficiently. Essentially, we do a population of cells. Each of the cells has a different guide RNA, and each of these guide RNAs has a different knockout for the gene of interest. Then, we subject this population to DNA damaging agents and read out which guide RNAs caused selective sensitivity to the DNA damage in question. That gives us a very unbiased view of the response. What we're seeing - and this was anticipated by the body of work - is that this is very profound. It impacts many aspects of cell biology from DNA repair itself, to chromatin biology, to the cell cycle. For the first time, we're having a genetic view of the response to these DNA damaging agents in human cells.

Jan Witkowski: The agents used are both chemical and radiation?

Dr. Durocher: Exactly. DNA is very susceptible to attack, both from the physical environment, from chemical mutagens, but also from the biology. In fact, we have enzymes that attack DNA or use DNA as well, so we're using that whole space for our study. We've done radiation, we've done chemicals, and we've also done genetic perturbation that leads to DNA damage as a tool.
Jan Witkowski: Presumably, you have some sort of positive control in the sense that you're picking up genes and proteins that you would expect to.

Dr. Durocher: Exactly. What was so exciting when we started doing these studies is that we essentially in one fell swoop could rediscover what was known. In addition, we were able to pick up new things, and also pick up things that were really surprising as well. The power of the technique is such that you can really believe these results, especially because you've got all the known components as well.

Jan Witkowski: Do you pick up different things for different chemical agents depending on the precise damage to the DNA that's done?

Dr. Durocher: Absolutely. It's really remarkable. As you would expect, agents that have similar modes of action will pick up similar genes. We can even build relationships between agents based on the profiles they're generating. In many ways, we could use an agent that is an unknown, put it on cells, and by the profile, we could say what type of DNA damage it would cause.

Jan Witkowski: Ever since the Ames test, there's been a long-standing desire to have better screens for chemical mutagens.

Dr. Durocher: That's one of the objectives that we have in doing these types of experiments. We can probably develop signatures that will really tell us what types of lesions are generated. In some cases it's mixed, and we see this and we can start deconvolving that as well.

Jan Witkowski: Partly with an eye toward screening for environmental hazards, is this a particularly sensitive way of detecting damaging agents?

Dr. Durocher: Absolutely. Also, we can modify the system to make it even more sensitive. We can also partly disable certain genome stability mechanisms, to make the cells even more sensitive. This is something we've not yet completely explored, but the potential is certainly there to really build very sensitive biosensors through this approach.

(C) 2017 Durocher. This article is distributed under the terms of the Creative Commons Attribution-NonCommercial License, which permits reuse and redistribution, except for commercial purposes, provided that the original author and source are credited. 
Jan Witkowski: There's been a tremendous argument about "how much" makes an environmental hazard actually dangerous. If you can't have zero chemicals as the only safe level, as you develop ever more sensitive tests, this argument becomes even more contentious.

Dr. Durocher: That's a very good point. From my side, we're interested in the genetic architecture of these responses. Doing this as a readout is an interesting idea, but the interpretation of what that readout is something we think about more.

Jan Witkowski: Let's get back to the biology, then. You said you've been picking up things that were either not known or you would not have been expected to be involved. Can you give a couple of examples?

Dr. Durocher: In one particular DNA damaging condition that effects DNA replication, we find ribosome quality control genes coming up. This suggests there's cross talk between translation and some aspects of the quality control pathways that govern DNA replication. This is something we're actively working on. We don't really know exactly what is the nature of this cross talk, but this is the type of new biology we're hoping to find.

We're also seeing a number of RNA-binding proteins involved in multiple aspects of gene expression. That goes in line with this theme that we're seeing: this meeting of chromosome organization, gene expression, and the functional genome as well. That's maybe a little more expected, but this is something that we'll dig into also.

Jan Witkowski: These are proteins that are involved in the quality control of ribosome structure or function?

Dr. Durocher: These are involved in the rescue of stalled ribosomes when they counter either structures or problems during translation. Essentially, it was the pathway that leads to its rescue, or its degradation, or its removal from the nascent transcript. Probably, what we're having is aberrant proteins being produced, and then these somehow interfere with DNA replication, in this case. What these proteins are is an active area of study in the lab.
Jan Witkowski: How does DNA repair play into the overall structural organization of the chromosome? Or is it the other way around?

Dr. Durocher: I think there's a very profound interaction between these: the quality control of the DNA molecule itself, and both the overall chromosome organization and chromosome segregation. As a quick example, homologous recombination is a DNA repair process that uses homology on other chromosomes to repair DNA damage. In the process of homologous recombination, you create these joint molecules. If these are not resolved in time, they lead to problems in chromosome segregation, because the chromosomes are physically linked together. There are a number of instances where you have this type of feedback.

The other way, during, for example, homologous recombination, the damaged DNA needs to find a homologous sequence. How does it search for this homologous sequence in the nuclear environment? Now you're going from the whole chromosome, to helping with the repair. Chromosome organization, in that sense, is also very useful.

Another thing we've been working on the past few years is that a number of DNA repair pathways are actually suppressed during chromosome segregation. Why? Maybe it's to avoid these contacts between chromosomes. These are the type of questions where there's a really nice interplay between chromosome organization and structure and DNA repair.

Jan Witkowski: Are there processes involved in DNA repair that are integral to chromosome dynamics?

Dr. Durocher: Yes. For example, the cohesin complex, which is really important for shaping the structure of the chromosomes and is also involved in keeping the newly replicated sister chromatids together. They play an important role in the DNA repair process as well. Almost at every stage of organization, from the unit of the nucleosome to the unit of the chromosome and how it's folded in the nucleus, there's a really intimate association with the DNA repair processes. 


\section{$\$_{\text {CSH\& }}^{\infty}$ Cold Spring Harbor Symposia SYMPOSIA}

\section{A Conversation with Daniel Durocher}

Cold Spring Harb Symp Quant Biol 2017 82: 389-390 originally published online April 2, 2018 Access the most recent version at doi:10.1101/sqb.2017.82.034546

Creative This article is distributed under the terms of the

Commons http://creativecommons.org/licenses/by-nc/4.0/, which permits reuse and

License redistribution, except for commercial purposes, provided that the original author and source are credited.

Email Alerting Receive free email alerts when new articles cite this article - sign up in Service the box at the top right corner of the article or click here. 